\title{
Del campo a la periferia de la ciudad, la omnipresente sombra de la violencia. Campesinos desplazados forzados en Colombia caminan de la mano del eterno retorno a la violencia: vulneración y potencia de vida
}

\author{
Myriam Ocampo Prado ${ }^{a^{*}}$ \\ Mábel Martínez Carpeta ${ }^{b}$ \\ Sandra Liliana Zuluaga Tapiab \\ alnvestigadora. Bogotá, Colombia \\ buniversidad Externado de Colombia. Bogotá, Colombia
}

\begin{abstract}
Resumen: La migración forzada de pobladores rurales que huyen para salvaguardar su vida constituye en Colombia el fenómeno del desplazamiento forzado originado por la confrontación violenta instigada por grupos armados. Los campesinos abandonan su vivienda en el campo para ubicarse en la periferia de las capitales. La exigencia de cambiar de lugar de permanencia transforma la idea acerca de si mismos y del espacio que ocupan, su ubicación física en el lugar de llegada les comunica las condiciones precarias que les rodean al encontrarse deslocalizados y desintegrados del espacio tal como lo habían construido para sí y su familia. El trasegar físico y emocional caracteriza el desarraigo, comprender la insistencia por reinventar un lugar para sí mismos en el espacio urbano pone en relieve las nuevas prácticas que van delineando territorialidades en medio de conflictos de convivencia con los pobladores ya establecidos en el entorno urbano donde deben estabilizar sus condiciones de vida.
\end{abstract}

Palabras claves: Desterritorialización, reterritorialización, nuevos pobres, potencia de vida.

\section{Introducción}

La violencia organizada en Colombia relacionada con el conflicto político, social y económico que vive el país desde hace seis décadas ha obligado a un número elevado de pobladores rurales a trasladarse a ciudades capitales, o intermedias, donde la presencia estatal les transmite la idea que pueden contar con seguridad y garantía para susvidas. Sin embargo, en la ciudad la supervivencia no está asegurada, lograr la alimentación, vivienda, empleo, seguridad, recreación, los remite a ver que las condiciones que los rodean son de precariedad; sus limitadas habilidades para trabajar en labores urbanas limitan, a su vez, la posibilidad de acceder a un empleo remunerado suficientemente para atender a las necesidades de subsistencia.

En el espacio de la periferia urbana donde llegan, escasean los servicios, y las viviendas son deleznables, inciertas, sobrepobladas; el lugar donde habitar y vivir es difícil de constituir. Un territorio, donde reconstruir el arraigo que requieren para reinventar así mismo sus vidas después de los largos periodos de tiempo como desplazados en proceso de reubicación, es esquivo y a veces parece inalcanzable. La aspiración de llevar una vida que integre las expectativas acerca de sí mismo y respecto a los suyos se ve confrontada por las condiciones que les exigen.

La noción de territorio se refiere a lo que el geógrafo Rogério Haesbaert (2009), por su parte, señala respecto a esta noción: El territorio es algo inacabado, realidad en permanente movimiento, sometida a procesos de dominio y control (político-económico) y/o de apropiación

* Autora correspondente: myriamocampo@yahoo.com (simbólico-cultural) que realizan los grupos humanos en un espacio determinado. Así, es pertinente agregar que cuando se construye un territorio, un grupo humano debe hacerlo suyo, nombrarlo, darle sentido, hacer de éste "su lugar" y adaptarse a la pobreza y marginalidad circundante. En un juego de dicotomías sus aspiraciones también le reiteran el imperativo de seguir adelante en la búsqueda de condiciones que dignifiquen la existencia.

Este artículo es producto de las reflexiones desarrolladas en el marco del proyecto Desplazamiento forzado y territorio: interacciones y transformaciones, con el objetivo principal de comprender la relación material y simbólica, que la población desplazada forzadamente por la violencia construye con el nuevo territorio y la percepción de los antiguos residentes respecto a la transformación del territorio,donde llegan a ubicarse los desplazados en las áreas urbanas. Se trabajó con cuatro grupos poblacionales: Afrocolombianos desplazados del pacífico colombiano reasentados en la ciudad de Bogotá D.C.; indígenas-campesinos desplazados de la región del Alto Naya en la zona sur de la región pacífica reasentados en la Finca La Laguna en el municipio de Timbío, departamento de Cauca; mujeres jefes de hogar desplazadas de 4 departamentos de la región caribe (Córdoba, Guajira, Antioquia y Bolívar) reasentadas en la ciudad de Montería, capital del departamento de Córdoba y campesinos desplazados de varias regiones del nororiente colombiano (Catatumbo, en Norte de Santander, Arauca, y del sur de los departamentos de Bolívar y Cesar), reasentados en la ciudad de Cúcuta, departamento Norte de Santander, en la frontera con Venezuela. 
El proyecto Desplazamiento forzado y territorio: interacciones y transformaciones, financiado por Colciencias, es una investigación que se desarrolló entre los años 2010-2012 en la Universidad Externado de Colombia, Centro de Investigación sobre Dinámica Social, (CIDS). El equipo completo de investigadores estuvo conformado por Myriam Ocampo, psicóloga social y directora de la investigación, Philippe Chenut, geógrafo, Mayerlin Ferguson, psicóloga social, Paola Forero, psicóloga, Edy Corredor, estudiante de geografía y las dos titulares de este artículo, Mabel Martínez, antropóloga y Sandra Zuluaga, filósofa quien fue investigadora invitada a reflexionar sobre los resultados de los estudios de caso.

\section{Migración forzada por la violencia en Colombia, transformación de las territorialidades}

Profundizar en la experiencia del territorio, según es vivido por pobladores de regiones rurales donde se han desplegado durante décadas acciones y confrontación armada entre actores del conflicto político colombiano, evidencia escenarios los cualesla violencia ejercida por diversos grupos, legales e ilegales, se enseñoreó en los territorios y los transformó en espacios de guerra, sin garantías de futuro. La amenaza de muerte rompió la relación establecida con la vida y se convirtió en el referente de la cotidianidad; la amenaza impuso la decisión de huir.

Con la migración forzada los pobladores sintieron la pérdida de la vida tal como solían experimentarla y organizarla. La huida es búsqueda de un espacio alternativo donde el peligro de muerte y la imposición del poder de las armas no fueran la única manera de imaginar un espacio para desarrollar su modo de vida. El proceso de desterritorialización como ruptura abrupta en la realidad que vivían los pobladores lleva consigo las secuelas del conflicto armado, desconfianza, dolor por el desarraigo, miedo, violencia, discriminación.

Si se entiende la territorialidad como la relación que establece el sujeto con el territorio donde ha vivido y establecido una noción de estar en el mundo, que Haesbaert (2009) recalca como "cada uno de nosotros necesita como un recursos básico territorializarse. . en un sentido múltiple y relacional" (p. 1), se puede comprender la desterritorialización como el proceso de ruptura, instigada por la violencia, de la relación con dicho territorio que era apropiación de las condiciones de vida tal como solían desenvolverse con un marco cultural y natural; la desterritorialización se va convirtiendo en deconstrucción de la relación con el lugar de origen, desde la disponibilidad de una vivienda y domicilio fijo hasta el sentido y significado asociados y atribuidos a los lugares habitados y recorridos.

Esta investigación aportó bases para construir una noción de territorialidad como apropiación e internalización del espacio en términos pragmáticos, el espacio que se domina y se conoce, el espacio donde encontrar lo que se necesita y desea, que imbrica al sujeto con el lugar donde ha vivido experiencias privilegiadas, no necesariamente placenteras, ya sea como su territorio de origen o como su territorio de relaciones sociales y productivas, es territorialidad como apropiación del espacio vivido en tanto referente que da forma a la imagen de sí mismo y a las aspiraciones frente a la realidad en la cual se enmarca la experiencia y adquiere carácter determinante de la existencia.

En un sentido cercano el geógrafo Monnet (1999) señala la relación con el territorio como territorialidad o sistema de valores atribuidos a ese espacio físico que además se articula a un sentimiento de pertenencia y apropiación. Esta construcción de Monnet da forma a un sistema socio-territorial constituido por la coexistencia de una noción triádica compuesta por el territorio-territorialidad-territorialización que delimita el campo de actividad del sujeto.

La territorialización se entiende como el sistema de acciones que se despliegan a partir del sistema de valores componente de la territorialidad. Esta, a su vez, como la relación que entabla el ser humano con el entorno en el que habita, señala una forma específica que tiene un grupo humano de relacionarse con dicho entorno. Si se tiene en cuenta que el grupo social de migrantes forzados proviene de sectores rurales del país, se debe señalar que la especificidad de su territorialidad corresponde a una territorialidad de carácter rural. Este carácter se cualifica teniendo en cuenta un complejo interactivo entre naturaleza, trabajo y sociedad (Domínguez, 1992). La conceptualización de Correa (1996, citado por Montañez \& Delgado, 1998) sintetiza el significado de territorialidad como concepto: "Conjunto de prácticas y expresiones materiales y simbólicas capaces de garantizar la apropiación y permanencia de un determinado territorio por un determinado agente social" (p. 124). En este sentido, la territorialidad rural que aquí se habla se compone de un conjunto de prácticas y sentidos que los pobladores rurales habían construido en su territorio de origen. Territorialidad que les daba un dominio de su vida y de su futuro como grupo social. La migración forzada, como evento infortunado, genera una ruptura con esta territorialidad pasada, que se anhela y se añora.

\section{Venir de la territorialidad rural}

La especificidad de la territorialidad rural corresponde a un modo de vida en quelas poblaciones se organizan en torno al trabajo de la tierra. El modo de vida en lo rural representa "un complejo interactivo entre naturaleza, trabajo y sociedad" (Domínguez, 1992, p. 100), dicha representación expresa que las poblaciones rurales poseen una organización formal, comportamiento individual y actitudes sociales, estrechamente unidos entre sí para el propósito de labrar la tierra con herramientas simples y trabajo humano como según este autor, indicaba Fei (1946, citado por Domínguez, 1992).

El modo de vida que se lleva en lo rural no señala precisamente una homogeneidad para todos los pobladores rurales. Se conoce que este modo de vida depende de las condiciones socioeconómicas de cada poblador, de la 
región a la que pertenezca, de las costumbres heredadas etc. Sin embargo, el modo de vida en lo rural plantea una serie de generalidades que caracteriza y abre la posibilidad de referirse a una territorialidad rural. Vivir y subsistir del trabajo agrícola es la principal característica de los pobladores rurales. El trabajo en familia, con una cosmovisión que pone la naturaleza en el centro de la relación con el mundo, las familias característicamente extensasyla educación de los hijos dentro de los valores del trabajo dan contenido al sujeto social que habita en lo rural. El trabajo agrícola - el cultivo y cosecha de productos propios de su dieta cotidiana - representa la autonomía alimentaria.

Las poblaciones rurales que se vieron forzadas a migrar a sectores urbanos del país significan la territorialidad rural evocando una serie de aspectos relacionados con la vida que llevaban asociadoscon la práctica de la agricultura, la pesca, la caza, el acceso a recursos naturales, la extensión territorial que comprendía el espacio donde ubicaron su vivienda, que ratifican la ruptura abrupta con su territorio debido a la expulsión infligida por los grupos armados. Éstos hechos llevaron a los migrantes a desplazarse por rutas de acceso a zonas urbanas cercanas y zonas de tránsito por donde evadir el peligro que los acechaba.

\section{Recrear unterritorio. Reterritorializarse}

Los nuevos lugares donde migran en busca de protección y cobijo, como es el caso de los desplazados sujetos de los estudios de caso adelantados, son territorios de precariedad y limitación; los desplazados al momento de procurar reubicarse en entornos urbanos empiezan a ser conscientes que la violencia también acecha en los barrios donde llegan, además chocan de frente con el conflicto social que los rodea: pobreza, marginalidad, inseguridad alimentaria. Esta situación impacta la dinámica familiar, sus hijos se ven influidos por un cúmulo de ambigüedades respecto a la alimentación, el albergue o lo permitido, que hacen quela educación no sea el patrón de intercambios propios de la vida rural sino un referente del exilio que les anuncia "el riesgo [inminente] de ser nadie" (Roelens, 2002, p. 34).

Sin embargo, imaginar el entorno urbano les genera sueños de recrear la vida en un escenario de seguridad y nuevos retos, reconstruir un territorio. Sin embargo, reanudar la idea de plenitud se traduce en una lucha por engarzar el proceso de reterritorialización, éste revela distintas dificultades como la de reinventar una idea de sí mismo luego del daño causado por la violencia, en realidad muchos de los desplazados forzados por causa de hechos violentos se encuentran de frente con una suerte de trashumancia acompañada de un sentimiento de estar excluido.

Esta lucha es al mismo tiempo acicate para activar la propia potencia de vida ante el riesgo de la muerte, de la pérdida sin esperanza; es potencia ante todo frente al imperativo de establecerse, de buscar restablecer un territorio para superar la condición de migrante forzado. Este proceso pone en relación a los desplazados forzados con las poblaciones residentes en las ciudades de arribo.
Allí se hace evidente un escenario de borrosidad de la convivencia; los nuevos migrantes urbanos con estatus de víctima del conflicto armado, como los ha denominado la Ley de Víctimas y Restitución de Tierras, Ley número 1448 de 2011, promulgada en Colombia, y los residentes que ya estaban establecidos en ese entorno3, quienes a su vez son migrantes expulsados de sus lugares y territorios en otras épocas de violencia sucedidas en la historia del país, o desarraigados debido al impacto de desastres naturales, conforman grupos de pobladores que demandan asistencia del Estado, las grandes diferencias en el acceso a los recursos por parte de cada grupo generan tensiones, discriminación y exclusión mutua.

En adelante se denominará residentes a los habitantes que ya estaban establecidos en los lugares donde llegaron a ubicarse las familias desplazadas.

Este aspecto de las relaciones desplazados-residentes o ya establecidos ha sido poco estudiado dentro de las situaciones de interacción que hace referencia a consecuencias del conflicto armado en Colombia y es uno de los temas que se consideran en este artículo. En efecto, los residentes que habitan en los barrios donde llegan los desplazados perciben al migrante como competidor en la lucha por los recursos que ofrecen las instituciones públicas y privadas. En la medida que los antiguos residentes son desplazados de otras épocas, algunos de ellos debido al enfrentamiento violento entre los dos partidos tradicionales colombianos - el Partido Liberal y el Partido Conservador - en los años cincuenta del siglo XX, dentro del cual estas personas fugitivas también sufrieron de la violencia de entonces no recibieron ningún apoyo institucional al momento de su llegada a la ciudad y, por esto, consideran ilegitimo que los desplazados de esta época actual accedan a ayudas a las que ellos mismos bajo condiciones similares no tuvieron acceso. Además, la situación limitada y para algunos precaria, en que continúan viviendo los residentes en la actualidad, los hace sentir que al tener necesidades semejantes, los beneficios deberían ser dirigidos en igual medida para ambos grupos. Por otro lado, los residentes consideran que las ayudas de las instituciones a los desplazados terminan incidiendo para que muchas personas no desplazadas simulen serlo.

La llegada de la población desplazada y, en algunos casos, la conformación de nuevos barrios, crean en los residentes una percepción del territorio como espacio de múltiples conflictos interpersonales el cual germina el sentimiento de ser tratado inequitativamente y una percepción de ilegitimidad de la situación que sobrevino con la llegada de los nuevos habitantes; empero, la nueva territorialidad urbana que se construye en la periferia demanda, del mismo modo, alianzas y arreglos para la vida en común. La potencia de vida, presente en ambas poblaciones, se expresa en los desplazados recientes quienes se debaten por encontrar el espacio que les devuelva su territorio perdido; losresidentes, por su parte, defienden la validez del esfuerzo invertido durante varios años, para lograr reconstruir un espacio y condiciones para continuar el propio camino. 


\section{Del territorio rural a la periferia de la ciudad}

El migrante forzado es sometido a vivir en la periferia de las ciudades en condiciones de pobreza. La inmersión en la sociedad urbana supone cambios drásticos, los saberes y experiencias acumulados en lo rural han quedado atrás y se presentan como obsoletos en la ciudad, sin embargo, éstos son la base que fundamenta la reterritorialización; la experiencia de territorialidad pasada será la base para iniciar un proceso de territorialización en la urbe la cualla territorialidad rural es para la población migrante el referente de ser y hacer como esquema imaginado para construir un lugar para sí en el mundo.

La ciudad impone otras territorialidades, en el espacio urbano periférico la exclusión social, la pobre$\mathrm{za}$, las limitaciones para conseguir el sustento presionan la innovación de la relación de apropiación del entorno como era conocida en la vida rural. En este aspecto de los conocimientos previos los contenidos y saberes que posee el sujeto orientan el despliegue de su acción y frecuentemente la búsqueda de transformar las condiciones que lo afectan. La noción de territorio resulta fundamental en tanto la relación de apropiación del nuevo espacio comienza a transformar en los sujetos desplazados los conocimientos y los referentes espaciales. En la ciudad los aspectos psicosocioculturales se reconfiguran. Giménez (2005) señala "el primer efecto cultural de la globalización es la reorganización general de la cultura en el marco urbano, a expensas de las culturas rurales y provincianas que tienden a colapsarse juntamente con sus perspectivas económicas" (p. 491). Si bien esta reorganización no supone una eliminación de las culturas rurales, sino una "reorganización".

Así puede afirmarse que la vida que debe llevar el migrante en los sitios de reubicación no revela "obsolescencia total" de lo conocido e incorporado en la territorialidad rural sino que éste construye en la ciudad su territorio y lo significa de acuerdo con prácticas rurales que perviven. Las relaciones sociales de parentesco, las prácticas de ocio y entretenimiento, la adecuación de las viviendas, el trabajo comunitario, las prácticas religiosas entre otros aspectos psicosocioculturales son expresiones de valores y de formas de ver y hacer que traen de lo rural a lo urbano, sin embargo, la reconfiguración y reorganización en la ciudad exige a los migrantes forzados integrar a su modo de vida la precariedad y carencia que encuentran en la periferia urbana.

Es territorialidad donde la relación urbanidad-ruralidad no desaparece sino que, por el contrario, se intensifica. Lefebvre (1968) destaca en la vida citadina la malla del tejido urbano lo cualpersisten islotes de ruralidad, territorios a menudo pobres (no siempre), poblados de campesinos de edad avanzada, que han sido despojados de todo lo que caracterizaba los valores y certezas de la vida como campesino. Esta territorialidad que hemos denominado urbana periférica, a partir de los resultados de los estudios de caso, revela las características reproducidas del espacio social en el queel modelo de la urbe impone perseguir estándares que definidos como "calidad de vida" como bienes y capacidad de consumo, a los cuales ellos logran muy limitadamente tener acceso.

Es una territorialidad en la periferia de la integración social que presiona a los pobladores rurales desplazados a convivir con otros "pobres rurales" quienes, en condiciones forzadas o no, migran a la ciudad en busca de nuevas opciones de vida que no han podido proveer en el campo (Castillo, Salazar, \& Pinzón, 2008). Así mismo, la nueva vida, las nuevas comunidades exigen incorporar y desplegar mecanismos de convivencia con habitantes urbanos en medio de situaciones conflictivas marcadas por la competencia por el acceso a los bienes escasos en estos sectores de la ciudad.

La necesidad de alianzas solidarias se hace evidente principalmente en las organizaciones comunitarias que se crean para construir proyectos de vivienda y mejoramiento del barrio. La organización y la institucionalización de grupos asociativos para el trabajo comunitario es una vía emprendida para combatir la exclusión social en la cual se ven inmersos debido a la vulnerabilidad económica, principalmente. No obstante, la vida de los pobladores rurales en la urbe se enfrenta también al embate desestructurante que se genera en la frecuente separación intergeneracional en la ciudad, la juventud como grupo de edad asimila rápida y velozmente la nueva vida en la ciudad (Lefebvre, 1968) a diferencia de los adultos. La territorialidad basada en la vida rural en la cual los distintos grupos de edad se vinculaban a las mismas actividades productivas y aspiraciones de futuro, en la urbe se transforman con frecuencia en vínculos inestables y aspiraciones disociadas entre las diferentes generaciones, los mayores dejan de ser considerados por los más jóvenes como un modelo a seguir. Los conflictos intergeneracionales, como expone Bourdieu (1991), evidencian la ruptura en dinámicas de relación y de abordaje de la realidad entre una u otra generación, revelan condiciones de existencia separadas, definición distinta acerca de prácticas que pueden ser adoptadas.

El limitado acceso a bienes y servicios básicos genera incertidumbre por el futuro de las generaciones más jóvenes, las deficiencias para garantizar el acceso a la salud, educación, trabajo, alimentación, vivienda generan incertidumbre y promueven entablar relaciones con instituciones y habitantes urbanos para acceder a subsidios o donaciones que se otorgan desde los organismos gubernamentales y no gubernamentales a desplazados y/o a población que ahora hace parte de los nuevos pobres de las ciudades. Estas relaciones aparecen como alternativa para mitigar el impacto de la carencia, pero, a la vez, los encadena al hilo de la dependencia de los subsidios.

\section{Los desplazados en la periferia de la urbe, reconfiguraciones territoriales y nueva vida en comunidad}

Los desplazados forzados de diferentes zonas rurales del país llegaron a diferentes ciudades del país con deseos de reubicarse. Este proceso lleva implícito una nueva dinámica de la vida en comunidad. Iniciar una relación con 
otros pobladores desplazados y migrantes, que provienen del campo y que se han establecido en la ciudad en diferentes épocas, evidencia el interés de reterritorializarse compartido por los diversos grupos que habitan en los barrios y asentamientos. Allí los migrantes forzados han tratado de retomar un proyecto de vida. La construcción de viviendas y del barrio son ejemplos de cómo esta población construye su propio territorio. Como señala Romero (2005), la adecuación de las viviendas para un espacio de vida da cuenta de la lucha emprendida para solucionar diferentes problemas en la búsqueda de hacer habitable el barrio como espacio de vida. En el conjunto de las representaciones sociales de sus habitantes la vivienda propia representa un bien que permite asegurar algo en el presente pensando en el futuro de la familia. Es una base desde la cual se mantiene el hogar y se intenta mejorar el nivel de vida. Es una forma de ascenso social respecto a cualquier situación como inquilinos vivida previamente al llegar a la ciudad.

La fundación de los barrios señala que en estos espacios antes deshabitados las comunidades se reasentaron y los reconfiguraron territorialmente. La expansión de las áreas periféricas muestra la forma en que dichos procesos migratorios, las comunidades desplazadas construyeron nuevos barrios en la ciudad. Los procesos "migratorios forzados" han generado la reconfiguración espacial de las ciudades del país a lo largo de la historia: "Los fenómenos migratorios forzados derivados de los conflictos alrededor de la apropiación y el control territorial han marcado la configuración del espacio nacional e influenciado las formas urbanas colombianas" (Sánchez, 2007, p. 23). La apropiación del espacio que realizan los desplazados, migrantes rurales y migrantes intraurbanos en los sitios de reubicación, se realiza en un nivel de organización social que va desde la familia hasta la comunidad. En este proceso el rol que cumplen las instituciones públicas y privadas incide considerablemente.

Sin embargo, el acceso a subsidios que otorgan instituciones públicas y privadas aparece como uno de los motivos de las disputas dentro de la comunidad pues los migrantes forzados son percibidos como los más beneficiados por estas entidades. Si bien esta situación podría ser sólo una percepción por parte de la comunidad que reside en los barrios a los que arriban los migrantes forzados, es claro que el derecho a la reparación que promulga la Ley de víctimas y de asistencia a desplazados da un "estatus" a los migrantes forzados.

Por primera vez en la historia de Colombia se expide una Ley exclusivamente dirigida a las víctimas del conflicto, con el fin de hacer efectivo su derecho a la reparación. Es una apuesta que por diez años implica un esfuerzo de todo el Estado colombiano para que las víctimas recuperen el modelo de vida que tenían antes de ser sacrificadas. (Ministerio del Interior y de Justicia, p. 18)

Este "estatus" genera que las instituciones gubernamentales y no gubernamentales asisten de manera prioritaria a la población migrante forzada por motivos de la confrontación armada.

Hurtado y Naranjo (2003) identifican cómo las relaciones sociales al interior de la comunidad se dan entre el conflicto y la solidaridad. Tales procesos experimentan una hibridación de antiguos habitantes pobres con nuevos pobladores entre los cuales se generan conflictos por la apropiación del territorio, pero a la vez relaciones de solidaridad en medio de las estrategias de supervivencia que se desarrollan. Los conflictos que se generan hacen parte del proceso de restablecimiento. De igual modo, las desconfianzas hacía uno u otro habitante del barrio señalan las barreras que crea la expansión urbana al involucrar en estas disputas por lograr un lugar y un espacio para sí mismo entre las múltiples personas de diferentes procedencias del país arribando a la ciudad. En este sentido, la vida en comunidad se despliega dentro de la heterogeneidad así como a través de historias de vida diferentes que confluyen en un mismo espacio.

El escenario social que se recrea en los barrios muestra además actores externos: ONGs, entidades públicas, empresas privadas, entidades internacionales, organizaciones ilegales (bandas de delincuencia común, expendedores de droga, organizaciones armadas etc.) entre otros, que presionan el nuevo territorio urbano en construcción por los migrantes, para sus fines e intereses. Estas presiones por parte de los actores externos a la comunidad son identificadas como causa de conflictos al interior de la trama comunitaria.

El término comunidad en este documento hace referencia a lo mencionado por Romero (2005) acerca de la comunidad recalcando la perspectiva antropológica: "connota vínculos de identidad (en la diversidad y la diferencia) y comunión, en la manera como las personas se piensan, se organizan, asimilan su pasado, asumen su presente y construyen su futuro" (p. 221). La conformación de las juntas de acción comunal en los diferentes espacios urbanos donde migran los pobladores rurales es expresión de la idea de comunidad afianzada en la lucha por hacer del barrio un lugar para un "buen vivir"; esta relación al espacio y a la idea de bienestar da cuenta, al mismo tiempo, de ideas de futuro creadas por la comunidad.

Bello y Mosquera (1999) han resaltado, a través de estudios realizados en barrios periféricos constituidos por habitantes que han sido migrantes forzados, la interacción entre actores para procurarse condiciones de permanencia, el proceso de desarrollo infraestructural y el tiempo de formación-consolidación de los grupos han dado forma a dinámicas particulares en las cuales se marcan diferencias en la forma como se relacionan entre pobladores y revelan los procesos de incidencia que se van encadenando en la búsqueda por la supervivencia y permanencia en el asentamiento. Las características que atribuyen Bello y Mosquera a los barrios "en proceso de consolidación" describen una lógica a través de la cual se han construido los espacios donde se desarrolla la territorialidad en lo urbano que es además, territorialidad en la periferia. 
La vida en comunidad que llevan los migrantes forzados no puede abordarse sin tener en cuenta el proceso de construcción y transformación de estos espacios a los que les arriban. Este proceso señala también el camino trazado, que continúa vigente, para quienes se establecieron en estos lugares en épocas previas y, sin embargo, siguen buscando poder contar con condiciones de vida familiar y social acordes a sus expectativas de dignidad y dignificación del entorno que habitan.

\section{Cuando se reactiva la "potencia de vida"}

Para las comunidades desplazadas por la violencia poder transformar sus condiciones de vida para reconstruir un territorio para sí mismos se funda en la esperanza de poder encontrar relaciones cercanas, forjar amistades honestas, solidaridades auténticas, escribir su historia como un relato significativo. En realidad, los lazos más cercanos siguen aguantando el peso de las pérdidas, este aguante ha ido conformando un tejido que impide al daño irreversiblemente sobre su sentimiento de potencia como ser humano portador de ilusiones. El compromiso con estas relaciones consigo mismo y con los otros los hace mantenerse en el presente.

Así, como ser padres, hijos, amigos, vecinos, trabajadores, gobernantes etc. (aprendizajes de un pasado cercano) continúa teniendo la fuerza de contar y reproducir modelos para la vida; pues son relaciones que aportan potencias a la vida, la apropiación de las mismas es vinculo que provee un valor a las acciones personales y colectivas, realizarse como citadino conservando los hábitos del campo, buscar que se haga justicia respecto a los hechos que cambiaron su vida. Estas relaciones en su continua actualización recogen del territorio perdido los nombres propios relacionados con los lugares que les eran especiales, el río, la montaña, la tierra, los rituales, la mujer, y se enraízan de nuevo en la ciudad periférica, como esperanza para la vida íntima, la vida productiva, la vida política. La memoria de lo que se trae (sea esta fantasmal o no) da sentido a la vida que ha sido dañada por los hechos de violencia.

La vida en la ciudad ubica a las víctimas de la migración forzada en la ignorancia relativa a su condición, lo que se transforma, a través de las políticas instituidas, en una condición temporal de desplazado que en realidad en una situación permanente de desposeído que ha creado un nuevo estado de cosas. Aquí se establece lo que puede denominarse una metamorfosis de sentido: La ciudad sitúa, ya no despoja como hizo la violencia rural sino que fija la desposesión en la precarización de la vida como pobre. Desterritorialización como campesino - reterritorialización como nuevo habitante en la periferia en la margen de lo que hace urbana la vida.

La desterritorialización, una pérdida del territorio a causa del despojo ejercido por grupos violentos, se hace real cuando se pierde la posibilidad y la capacidad de volver a realizar un vínculo fundamental entre saberes y raíces, entre palabras y territorios rurales. Suturar las heridas hechas a los saberes, a los sabedores y a las palabras, implica devolverles la realidad, la raíz, el territorio que los hizo posibles; así, el territorio, el entorno de origen o de procedencia, que nunca volverá a ser lomismo, trasciende su naturaleza local y de receptáculo y se convierte en un don de la condición de humanidad. Sanar el daño es construir un territorio para "la humanidad que somos", así de singular, única y propia, porque no hay humanidad sin territorialización, ni valores, sentires y prácticas. El territorio pasa de ser una generalidad como superficie de dominioa convertirse en un derecho: derecho a construirlo como espacio propio, como espacio que da cuenta y referencia de lo que es en sí mismo.

Lo que se puede hacer, lo que se debe, lo que se quiere vivir y lo que se hace para que sea posible, supone en la ciudad decisiones nuevas, compromisos con ese nuevo "estar en el mundo". Esa metamorfosis que los desplaza de "ser sabedores" al "lugar de la ignorancia", los dispersa. Regresar a las voces comunes, es decir, a la narración de sí mismos, es la construcción de relatos que suturen lo colectivo, aún disperso en las pérdidas que les cambiaron sus vidas y lo personal que protege la vida íntima. Allí se muestra inevitablemente la deuda que tenemos con las poblaciones desplazadas: permitirles ser actores con nombre propio y no víctimas (a secas) de la historia nacional.

Se podría decir que en el proceso de migración forzada acaece la nuda vida (Agamben, 1999, citado por Villacañas de Castro, 2006, p. 16) vida en el sometimiento al despojo, desprovista del carácter que aportaba la singularidad de la vida enraizada, nuda vida también atravesada por el acontecimiento moderno reconocido por Foucault sometido a un poder cuya máxima aspiración es invadir la vida enteramente, mediante la intromisión de la lógica soberana en todos los ámbitos. Esto entraña un cambio cuantitativo en la forma en que ésta se aplica, el poder reduce el ser humano a una identidad concreta, la identidad de desplazado. En la sociedad urbana el despojado, el desplazado del poder, que administraba en su lugar de origen o de procedencia, parece encontrarse en el ámbito de la administración de la vida entera por unos poderes externos. Dependiendo de ese poder, se manifiesta la potencia fundamental o la voluntad inagotable de dar forma a la vida, tomando distancia del acto opresor que lo ha forzado a la nuda vida.

Nuda vida, es decir, la vida a quien cualquiera puede dar muerte aunque ella misma es insacrificable. Una oscura figura del derecho romano arcaico, en que la vida humana se incluye en el orden jurídico únicamente bajo la forma de su exclusión, no la soberanía sino los códigos del poder político revelan el arcaísmo de disponer de la vida del otro.

Dicha manifestación se presenta de modo contradictorio entre ellos, dice Agamben en palabras de Villacañas de Castro (2006): 
el hombre no puede evitar dar forma a su vida, como tampoco que esta misma forma se le presente solamente como una posibilidad que no se agota en sí misma. En este contexto, el pensamiento será aquello que enlazará al hombre con su dimensión potencial y lo hará a través de su experiencia de pensar, es decir, al reflexionar sobre el propio carácter siempre abierto de la inteligencia y, por lo tanto, de la vida del hombre. (p. 14)

Através de este pensarse como multitud, retomando a Spinoza, "la multitud es el arquitrabe de las libertades civiles" (Spinoza, 1677, citado por Virno, 2003 , p. 3) podemos decir que el encuentro en multitud es engranaje de relaciones-potencia, es el contar, aun en la memoria, con la huella de "los nombres propios", los "territorios fundamentales", los vínculos perdidos entre saberes y raíces, palabras y territorios. El encuentro de los "desterritorializados", que caminan no hacia los acuerdos soberanos (como propone el Estado Hobbesiano) sino hacia los "nombres propios", es experiencia potenciadora de alternativas de reterritorialización.

\title{
Do campo à periferia da cidade, a onipresente sombra da violência.Os deslocamentos forçados na Colômbialevam ao eterno retorno à violência: violação e poder da vida
}

Resumo: A migração forçada das populações rurais que fogem para salvar suas vidas é umfenômeno de deslocamento causado pelo confronto violento incitado por grupos armados na Colômbia. Os agricultores deixam suas casas no campo para viverem na periferia das capitais. A mudança forçada do local de permanência transforma a ideia sobre si mesmo e sobre oespaço ocupado, sua localização física no local de chegada mostra as condições precárias que os rodeiam encontrando-se sem localização e desintegrados desse espaço como construíram para si e sua família. Este trânsito físico e emocional caracteriza a noção de desenraizamento, poisse torna chave para entender a luta porreinventar um lugar para si no espaço urbano onde emergem novas formas de apropriação do espaço. Este trânsito também traz o conflito de coexistência entre recém-chegados e migrantes residentes, o território aparece como espaço onde deve conseguir acesso à casa própria e estabilizar suas condições de vida.

Palavras-chave: desterritorialização, reterritorialização, novos pobres, poder da vida.

\section{From the countryside to thesuburbs of thecity, the omnipresent shadow of violence. The forced displacements in Colombia lead to the eternal return to violence: violation and the power of life}

\begin{abstract}
The forced migration of rural populations, fleeing to save their lives, is a phenomenon of forced displacement caused by the violent confrontation incited by armed groups in Colombia. Farmers leave their homes in the field to livein the suburbs of capital cities. The forced change of residence transforms the idea of own selfand about the space occupied, their physical location in the place of arrival shows the precarious conditions surrounding them, lying outsourced and crumbled from this space they built for themselves and their family. This physical and emotional transit characterizes the notion of uprooting, because it becomes key to understanding the struggle to reinvent a place for them in the urban space where new ways of appropriation of space emerge. Such transit also brings the conflict of coexistence between newcomers and resident migrants, the territory appears as a space where they must acquire their own house and stabilize their living conditions.
\end{abstract}

Keywords: deterritorialization, reterritorialisation, new poor,power of life.

\section{De la ferme à la périphérie de la ville, l'ombre omniprésente de la violence - les déplacements forcés en Colombie conduisent au retour à la violence: violation et puissance de vie}

Résumé: La migration forcée des populations rurales fuyant pour sauver leurs vies est unphénomène de déplacement forcé provoqué par la confrontation violente, incitée par les groupes armés en Colombie. Agriculteurs quittent leur foyerpour vivre à la périphérie des villes capitales. Lechangement forcé du lieu de permanence transforme leur idée d'eux-mêmes etde l'espace qu'ils occupent; leur emplacement physique dans le lieu d'arrivée communique les conditions précaires qui les entourent,les rendent désintégrés et deracinés de la façon laquelle ils avaient construit pour eux-mêmes et leur famille. Ce transit physique et émotionnelle caractérise la notion de lorsque devient clé pour comprendre la lutte pour une place pour se réinventer dans l'espace urbain où émergent de nouvelles territorialités. Ce transit implique aussi le conflit de la coexistence entre nouveaux arrivants et migrants résidents, dans lequel le territoire apparaît comme un espace où peut-onparvenir à l'accès à une propriété et à stabiliser lesconditions de vie.

Mots clés: déterritorialisation, reterritorialisation, nouveaux pauvres, puissance de vie. 


\section{Referencias}

Agamben, G. (1999). Homo Sacer: el poder soberano y la nuda vida. Valencia: Editorial Pre-Textos.

Bello, M., \& Mosquera, C. (1999). Desplazados, migrantes y excluidos: actores de las dinámicas urbanas. In F. Cubides \& C. Domínguez (Eds.), Desplazados, migraciones internas y reestructuraciones territoriales (pp. 456-474). Bogotá: Centro de Estudios Sociales/ Universidad Nacional de Colombia.

Bourdieu, P. (1991). El sentido práctico. Madrid: Taurus.

Castillo, M., Salazar, B., \& Pinzón, F. (2008). ¿Cuál es el peso de las redes en la pobreza urbana y la exclusión social de los desplazados? In A. Ziccardi, Procesos de urbanización de la pobreza y nuevas formas de exclusión social (pp. 249-276). Bogotá: Siglo del Hombre.

Domínguez, R. (1992). Caracterizando al campesinado y a la economía campesina: pluriactividad y dependencia del mercado como nuevos atributos de la "campesinidad". Recuperado de http://www.magrama.gob.es/ministerio/ pags/biblioteca/revistas/pdf_ays/a066_04.pdf

Giménez, G. (2005, julio-septiembre). Cultura, identidad y metropolitanismo global. Revista Mexicana de Sociología, 67(3), 483-512.

Haesbaert, R. (2009). El mito de la desterritorialización: del fin de los territorios a la multiterritorialidad. Recuperado de http:/www.unc.edu.ar/extension-unc/vinculacion/ instituciones-sociales-y-salud/acciones-realizadas/ actividades-realizadas/2010/seminario-extensionistaaportes-de-la-epidemiologia-comunitaria/unc-seu-mitodesterritorializacion.pdf

Hurtaso, D., \& Naranjo, G. (2003). Desplazamiento forzado y reconfiguraciones urbanas: algunas preguntas para los programas de restablecimiento. In Destierros y desarraigos: memorias del II Seminario internacional, desplazamiento: implicaciones y retos para la gobernabilidad, la democracia y los derechos humanos (pp. 271-287). Bogotá: CODHES-OIM.
Lefebvre, H. (1968). El derecho a la ciudad. Barcelona: Península.

Ministério Del Interior y de Justicia. (2011). LEY 1448 de víctimas y Restitución de Tierras "Por la cual se dictan medidas de atención, asistencia y reparación integral a las víctimas del conflicto armado interno $y$ se dictan otras disposiciones." República de Colombia. http://www.unidadvictimas.gov.co/normatividad/ LEY+DE+VICTIMAS.pdf

Monnet, J. (1999). Las escalas de la representación y el manejo del territorio. In B. Nates (Comp.), Territorio y cultura, del campo a la ciudad. Últimas tendenciasen teoría y método (pp. 63-70). Quito: Abya-Yala.

Montañez, G., \& Delgado, O. (1998). Espacio, territorio y región: conceptos básicosparaun proyectonacional.Cuadernos de Geografia, 7(1-2), 120-134. Recuperado de http://www. geolatinam.com/files/Montanez_y_Delgado._1998.pdf

Roelens, T. (2002). Sal de tu tierra... a la tierra que te mostraré. Palimpsesto, 2, 34-35.

Romero, Y. (2005, enero-junio). Tramas y urdimbres sociales en la ciudad. Revista Universitas Humanística, 61, 217228.

Sánchez, L. (2007). Migración forzada y urbanización en Colombia, perspectiva histórica y aproximaciones teóricas. In Seminario InternacionalProcesos Urbanos Informales, Universidad Nacional de Colombia, Bogotá.

Virno, P. (2003). Gramática de la multitud. Buenos Aires: Colihue.

Villacañas de Castro, L. S. (2006). La política de la potencia en Giorgio Agamben. Valencia: Universidad de Valencia.

Recebido: $16 / 05 / 2014$

Revisado: 31/07/2014

Aceito: 09/02/2015 